\title{
Estudo sobre o Impacto dos Espaços Interativos dos Museus de Ciências no Processo de Ensino e Aprendizagem
}

\author{
Ana Grasielle Dionísio Corrêa ${ }^{1,2}$, Amanda Ferraz Silveira Mello ${ }^{2}$, Irene Karaguilla \\ Ficheman $^{2}$, Roseli de Deus Lopes ${ }^{2}$
}

1- Faculdade de Computação e Informática - Universidade Presbiteriana Mackenzie Rua da Consolação, 930 - Consolação, São Paulo - SP, 01302-907

2 - Escola Politécnica - Universidade de São Paulo

Av. Prof. Luciano Gualberto, travessa 3, nº 158 - 05508-970 - São Paulo - SP - Brasil

amanda.mello@mackenzista.com.br, ana.correa@mackenzie.br,

irene@lsi.usp.br, roselielsi.usp.br

\begin{abstract}
Science museums interactive spaces enable public interactive and dynamic contact with scientific knowledge. The Catavento Cultural museum offers, among others, the attraction "Aventura no Sistema Solar" designed to simulate a space travel through a projection system and interactive activities presented as games. This study aimed to investigate the cognitive and affective gains with interactive games of this attraction. A study with 128 elementary and middle school students led us to conclude that, in addition to enabling a pleasant experience, this kind of simulation contributes to the learning process related to physics and mathematics.
\end{abstract}

Resumo. Espaços interativos, em museus de ciências, possibilitam que o público possa entrar em contato com conhecimentos científicos de forma interativa e dinâmica. $O$ museu de ciências Catavento Cultural oferece, entre outras, a atração Aventura no Sistema Solar concebida para simular uma viagem espacial por meio de um sistema de projeção e atividades interativas apresentadas em formato de jogos. Este trabalho teve por objetivo investigar os ganhos afetivos e cognitivos com os jogos interativos desta atração. Um estudo com 128 alunos do ensino fundamental possibilitou concluir que, além de possibilitar uma experiência agradável de utilização, ajuda no processo de aprendizagem de assuntos relacionados à física e matemática.

\section{Introdução}

Os museus se constituem em um espaço educativo informal que complementa a aprendizagem, tanto dos alunos que frequentam as escolas, quanto do público em geral. Muitos museus podem ser considerados uma extensão da sala de aula por serem capazes de introduzir seu público no mundo científico e tecnológico [Valente, Cazelli e Alvez; 2005], [Marchi et al., 2007]. Além de exibir experimentos que demonstram fenômenos científicos básicos, abordados tradicionalmente em livros didáticos, os museus de ciências têm a possibilidade de tratar resultados de pesquisas de ponta de forma dinâmica e interativa: alunos e professores podem explorar conhecimento de forma inovadora, atrativa e motivadora [Ficheman et.al., 2008], [Martinazzo et al., 2009].

O Catavento Cultural e Educacional, por exemplo, situado na cidade de São Paulo, é um museu interativo dedicado às ciências. $\mathrm{O}$ museu está dividido em quatro espaços - universo, vida, engenho e sociedade - cada um contendo várias atrações. Uma delas é a "Aventura no Sistema Solar", que simula uma nave espacial, onde por meio de vídeos e jogos educativos, os participantes vivenciam uma aventura no espaço, entrando em contato com conceitos relacionados à astronomia, física e matemática. Durante a 
aventura na nave, os participantes entram em contato com planetas do sistema solar e realizam tarefas colaborativas por meio de jogos digitais.

As vantagens que os jogos digitais trazem para a educação são várias e são discutidas por diversos pesquisadores da área como, por exemplo, para ensino de inglês [Levay et al., 2015]; matemática [Pierini, Valentim e Cardoso; 2012], [Henrique et al., 2015]; música [Corrêa et al., 2012]; entre outros. Não somente o ensino fundamental e médio se beneficiam dos jogos digitais, como também o ensino superior, como é o caso da disciplina de programação [Scaico, et al.,2012]; [Pontes et al.,2013]; engenharia de software [Savi et. al., 2011]; usabilidade [Ferreira et al., 2014] entre outros.

O objetivo deste estudo foi investigar os ganhos afetivos e cognitivos com os jogos digitais da atração "Aventura no Sistema Solar", do Museu Catavento Cultural. O estudo foi realizado com 128 alunos do ensino fundamental I e II matriculados em escolas públicas. Uma pesquisa realizada na literatura serviu de referencial teórico para a construção de um modelo de avaliação que possibilitou identificar: (a) o nível de motivação dos estudantes ao usarem os jogos; (b) se os jogos oferecem uma experiência agradável de utilização; e (c) o grau de retenção de informação pós-jogo.

\section{Museus de Ciência e Educação}

Os museus vieram mudando ao longo do tempo, e muitos deixaram de ser um simples espaço de apresentação de artes para ser uma extensão da sala da aula. De acordo com Vieira et al. (2005), os museus e centros de ciências estimulam a curiosidade dos estudantes e oferecem a oportunidade de suprir, ao menos em parte, as carências das escolas com a falta de laboratórios, recursos audiovisuais, entre outros, reconhecidos por estimular o aprendizado. Em museus de ciências, os visitantes têm a oportunidade de protagonizar ações e descobrimentos, ou seja, convertem-se em sujeitos ativos, uma vez que têm uma relação direta com os aparatos por meio da manipulação ou da observação de como os outros os manipulam. Assim, o público experimenta de forma direta, viva e lúdica um fato científico [Valente e Maria, 2005] [Ficheman et al., 2008].

Através do movimento de interiorização de ciências no Brasil, surgiu o museu Catavento Cultural e Educacional, localizado na cidade de São Paulo. Inaugurado em 2009, foi concebido com a função de integrar a Ciência e os problemas sociais de uma maneira atraente e interativa. Possui cerca de 250 atrações em quatro seções cujos assuntos se interligam: Universo, Vida, Engenho e Sociedade [Lozada et al., 2012].

\subsection{A atração "A Aventura no Sistema Solar"}

A "Aventura no Sistema Solar" é uma instalação da seção Universo do Museu Catavento concebida para simular uma viagem espacial interativa por meio de um sistema de projeção e atividades interativas apresentadas em formato de jogos. Do ponto de vista pedagógico, as atividades propostas provocam nos participantes a reflexão sobre temas como fenômenos astronômicos e astrotécnicos, além de possibilitar a aplicação de conhecimentos sobre física e matemática. As atividades são realizadas em três momentos: ambientação, simulação e reflexão. A ambientação ocorre no início da atividade e permite a familiarização com o espaço de interação e o objetivo da missão espacial. A simulação propõe a interação dos participantes com o ambiente, por meio de jogos colaborativos. O momento de reflexão visa despertar nos alunos questionamentos sobre os assuntos abordados durante a visita ao espaço.

Por meio de uma cenografia que reproduz o interior de uma nave espacial, utilizando tecnologias de Realidade Virtual, narração, trilha e efeitos sonoros, a instalação aumenta a sensação de imersão nas atividades (Figura 1). As trajetórias da 
nave pelo universo são visualizadas por meio de um conjunto de televisores que exibem imagens do espaço, simulando suas janelas.

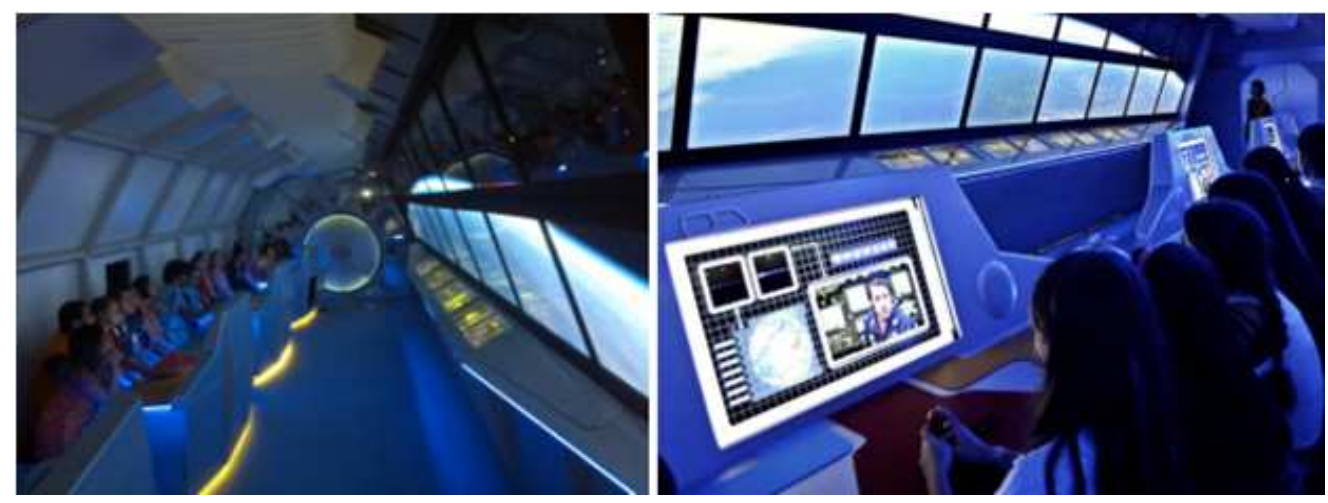

Figura 1. Ambientação da Instalação Aventura no Sistema Solar

Dentro da nave, um grupo de até 24 participantes é distribuído em quatro estações de trabalho. Cada estação é dimensionada para acomodar seis integrantes, que interagem com o sistema por meio de telas sensíveis ao toque (Figura 2a), joystick (Figura 2b) ou um conjunto de botões (Figura 2c).
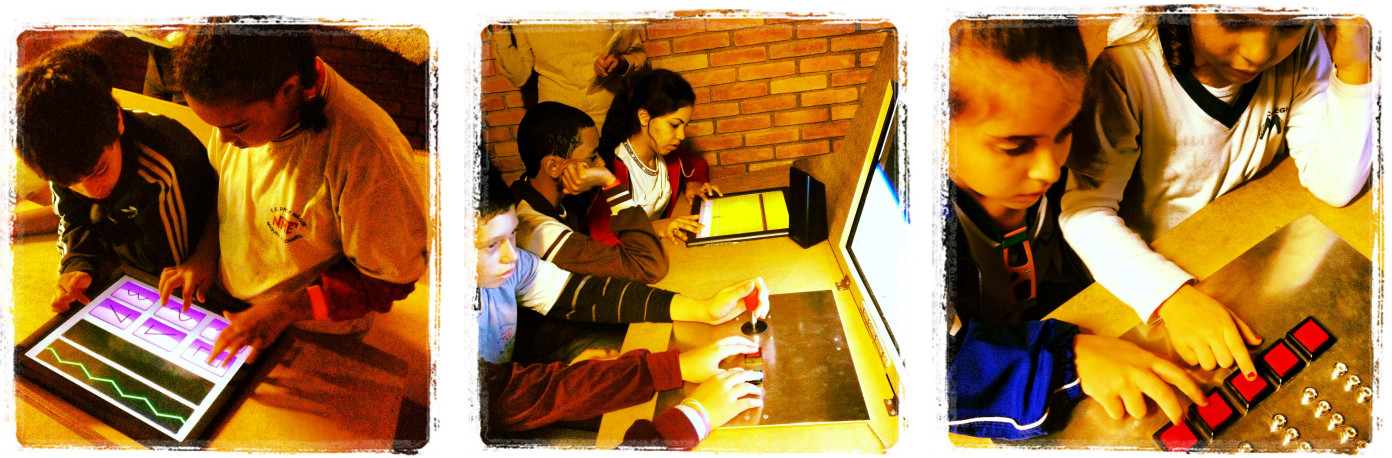

Figura 2. (a) Tela touchscreen; (b) Joystick; (c) Botões

Resumo das atividades da nave: Hélio, o personagem que representa o comandante explica os procedimentos para fazer a viagem espacial. Antes de fazer a decolagem, é necessário carregar as baterias da nave e alimentar os sistemas de energia solar. Este procedimento é implementado no jogo de calibrar os painéis solares. Após a decolagem, os estudantes recebem a missão de ajudar a tripulação da Estação Espacial Internacional que necessitam de mantimentos, então por meio de um jogo eles devem acoplar a nave junto à Estação Espacial Internacional e fazer a transferência dos mantimentos. Em seguida, os estudantes ficam sabendo que houve um problema com o telescópio Hubble, aprendem que existe um telescópio que capta imagens mil vezes mais que o olho humano e devem interagir com um jogo para consertar o telescópio. Os alunos começam a receber informações sobre Marte: sua cor é vermelha, foi descoberto que há água em estado líquido e que, portanto, pode existir vida em Marte. Um robô foi enviado à Marte para averiguar a existência de água, mas está preso nas rochas. Em seguida, é dada a missão de ajudar o robô (jogo salvar o robô em Marte). Os estudantes também recebem informações sobre Vênus que é conhecido como irmão gêmeo da Terra. É relatado que há lixo no espaço, então os estudantes recebem a missão de afastar o lixo espacial (jogo de afastar o lixo espacial). Em seguida, o comandante informa que retornarão para Terra. É feita a aterrissagem e o jogo termina.

\section{Modelos de Avaliação de Aprendizagem}

Para avaliar o nível de motivação dos estudantes foi utilizado o modelo proposto por Keller (2009), definido como ARCS (Atenção, Relevância, Confiança e Satisfação). 
Segundo o autor, a motivação, no contexto educacional, está relacionada ao engajamento voluntário em continuar a aprender sobre um determinado assunto e, para que isso ocorra, é preciso que o estudante: mantenha um nível satisfatório de atenção durante o experimento (A-Atenção); perceba que a proposta educacional seja consistente e o ajude a conectar o conteúdo com o futuro profissional ou acadêmico $(\mathrm{R}$ Relevância); obtenha sucesso nas experiências decorrentes de suas habilidades (CConfiança); experimente experiências positivas de aprendizagem acompanhadas de reconhecimento e recompensas (S-Satisfação).

Para avaliar se a experiência de utilização é satisfatória, foram utilizados os modelos propostos por Savi et al. (2010). Experiências decorrentes da interação com jogos, como por exemplo mudanças no estado emocional das pessoas. Assim, a avaliação da experiência de utilização pode ser feita mediante a avaliação dos elementos de interação, tais como: diversão, imersão, desafio, controle e interação social. A diversão proporciona sentimentos de prazer, relaxamento, distração e satisfação. Para os autores, uma experiência divertida é geralmente acompanhada do desejo de voltar a participar e de recomendá-la para os amigos. A imersão está relacionada com o engajamento e profundo envolvimento com o jogo. O tempo é um fator que possibilita verificar a imersão em jogo, por exemplo, onde o jogador não percebe o tempo passar e permanece horas ou finais de semana jogando interruptamente. O desafio está relacionado aos níveis de dificuldade da experiência e, estes, devem estar adequados ao nível de habilidade do jogador. Novos obstáculos, situações e variações de atividades devem estar apropriados para minimizar a fadiga do jogador e oferecer uma experiência que mantenha sua vontade de continuar participando. O controle está relacionado com a sensação de autonomia sobre a interface que deve ser fácil de aprender a usar. A interação social é medida por meio do envolvimento do participante com outras pessoas a fim de obter sucesso em grupo.

A Taxonomia de Bloom [Bloom 1956], foi utilizada para avaliar o grau de retenção de informação. Trata-se de uma estrutura que pode ser aplicada para planejar, projetar e avaliar a efetividade da aprendizagem definida em seis níveis: Conhecimento (lembrar informações sobre fatos, datas, palavras, lugares, procedimentos, etc.), Compreensão (captar o significado da informação), Aplicação (aplicar os conhecimentos em situações reais), Análise (identificar as partes e suas inter-relações), Síntese (combinar as partes para formar um todo) e Avaliação (julgar o valor do conhecimento). No modelo de avaliação proposto neste trabalho, apenas o primeiro nível da Taxonomia de Bloom foi considerado: Conhecimento, que envolve memória.

De acordo com as teorias cognitivas de aprendizagem [Moreira, 1999], acessar as informações que estão registadas na memória, traz influências diretas na aprendizagem, uma vez que a estrutura e o material a ser aprendido são em grande parte dependente do conhecimento retido na memória, ou seja, daquilo que o indivíduo já sabe e é capaz de recordar. O atual conhecimento não só influencia a aprendizagem de novos conhecimentos e informações, mas também o modo como esses conhecimentos e informações são organizados, de forma a serem recuperados no futuro.

\section{Metodologia da Pesquisa}

Trata-se de um a pesquisa empírica quantitativa e exploratória. Inicialmente foi feita uma pesquisa bibliográfica acerca dos espaços interativos de aprendizagem instalados em Museus de Ciências. Em seguida, foram definidos os objetivos da investigação, visando obter informações sobre os ganhos afetivos e cognitivos da atração "Aventura no Sistema Solar": (a) o nível de motivação dos estudantes ao usarem os jogos; (b) se os jogos oferecem uma experiência agradável de utilização; (c) o grau de retenção de 
informação. Em sequência, foi feita uma pesquisa na literatura em busca dos modelos de avaliação de aprendizagem e de avaliação de jogos educacionais.

Visando obter dados estatísticos, válidos no contexto da pesquisa quantitativa, ficou estabelecido que o tamanho da amostra deveria ser superior a 100 estudantes. Paralelamente, foi elaborado o modelo de avaliação, no qual foram incluídos: o modelo ARCS, de Keller (2009), para avaliar a motivação; o modelo de Savi et al. (2010) para avaliar a experiência com jogos (diversão, imersão, desafio, controle e interação social); e a Taxonomia de Bloom (1956), para avaliar o nível de conhecimento (retenção da informação).

Com base no modelo concebido, foram criados questionários de pré-teste e pósteste baseado nos parâmetros que compõem o modelo de avaliação (Tabela 1). Para avaliar o nível de conhecimento (cognição), foram feitas perguntas relacionadas aos conteúdos abordados nos jogos com a seguinte escala de respostas: Sim, Não e Não Sei. Essas perguntas foram feitas aos estudantes, individualmente, antes (pré-teste) e depois (pós-teste) de participarem da experiência.

Tabela 1. Questionários de Coleta de Dados

\begin{tabular}{|c|c|}
\hline Pré-teste e Pós-teste (cognição) & Pós-teste (afetiva) \\
\hline $\begin{array}{l}\text { 1. As naves espaciais utilizam } \\
\text { energia solar? } \\
\text { 2. A Estação Espacial } \\
\text { Internacional recebe } \\
\text { combustível e mantimentos } \\
\text { levados por uma pequena } \\
\text { nave não tripulada? } \\
\text { 3. Existe um telescópio no } \\
\text { espaço que enxerga mil } \\
\text { vezes mais que o olho } \\
\text { humano? } \\
\text { 4. Robôs são enviados ao } \\
\text { Planeta Marte para fazer } \\
\text { pesquisas? } \\
\text { 5. Existe vida em Marte? } \\
\text { 6. Existe lixo no espaço? }\end{array}$ & $\begin{array}{l}\text { Atenção: fiquei muito concentrado nos jogos. } \\
\text { Relevância: aprendi novidades sobre o sistema solar. } \\
\text { Confiança: consegui pontuar nos jogos. } \\
\text { Satisfação: me sinto feliz após jogar. } \\
\text { Diversão: achei os jogos muito divertidos; gostaria de } \\
\text { jogar novamente; } \\
\text { Imersão: nem vi o tempo passar enquanto eu jogava; } \\
\text { Desafio: queria continuar jogando. } \\
\text { Controle: achei fácil usar o controle dos jogos. } \\
\text { Interação Social (pergunta optativa): eu e meu colega } \\
\text { conseguimos interagir e jogar juntos. } \\
\text { Ranking dos jogos preferidos (pergunta optativa): } \\
\text { Marque com um X os jogos que você mais gostou: (a) } \\
\text { Calibrar os painéis solares; (b) Levar alimentos para a } \\
\text { Estação Espacial Internacional; (c) Consertar o } \\
\text { telescópio Hubble; (d) Decifrar mensagem de socorro; } \\
\text { (e) Salvar o robô em Marte; (f) Afastar o lixo espacial. }\end{array}$ \\
\hline
\end{tabular}

O questionário de pós-teste (afetiva), foi aplicado logo após a visitação. Foram acrescentadas perguntas relacionadas à motivação (atenção, relevância, confiança e satisfação) e experiência de interação com os jogos (diversão, imersão, desafio, controle e interação social). Estes itens foram apresentados em forma de afirmações para que os estudantes pudessem indicar seu grau de concordância baseado na escala de Likert de 5 pontos: variando entre "concordo totalmente" e "discordo totalmente". As duas últimas perguntas do questionário são optativas: a primeira para identificar se os estudantes gostariam de jogar em outra equipe e a segunda para classificar os jogos preferidos. 
Visando validar os questionários, bem como obter o tempo necessário de preenchimento dos mesmos, pelo público infanto-juvenil, foi realizado um estudo piloto com dois estudantes que visitaram a atração. A partir deste piloto ficou constatada a necessidade de realizar alguns ajustes de linguagem no questionário. Em seguida, foi feita a coleta de dados com 128 estudantes do ensino Fundamental I e II que participaram da atração durante um período de 6 dias. Os dados coletados foram tabulados em planilhas e organizados para análise. Por último, foram feitas as análises e discussões dos resultados.

\section{Apresentação e Discussão dos Resultados}

Os dados coletados foram organizados em três grupos: Geral (contendo toda a amostra, 128 participantes); FI (81 participantes do Ensino Fundamental I); FII (47 participantes do Ensino Fundamental II).

Com relação ao item (a) "nível de motivação dos estudantes ao usarem os jogos", dos 128 participantes, cerca de 90\% sentiram-se motivados:

- O nível de atenção (concentração) dos participantes com os jogos da nave foi satisfatório, com 90\% das respostas positivas (concordo e concordo totalmente);

- A confiança, variável relacionada ao sucesso das experiências, obteve $91 \%$ de respostas positivas, ou seja, a experiência ajudou os alunos a demonstrarem suas competências, ganhando assim, mais confiança nos jogos;

- A relevância do conteúdo dos jogos também foi satisfatória com 92\% de respostas positivas. Portanto, a atração apresenta uma proposta educacional consistente, do ponto de vista dos participantes.

- A satisfação foi imperativa com $95 \%$ de respostas positivas.

Analisando separadamente os dois grupos FI e FII, pode-se concluir que o FI manteve-se mais motivado durante a experiência com os jogos da nave, principalmente em relação ao item Satisfação, que foi maior na faixa etária (6 a 10 anos de idade). Constatamos, portanto, que esta experiência encanta mais o público infantil, dada as características de imersão, diversão, imaginação, entre outros atributos inerentes aos jogos e brincadeiras colaborativas.

Com relação ao item (b) "se os jogos oferecem uma experiência agradável de utilização", no geral, foi muito bom:

- A diversão, responsável pelos sentimentos de prazer, relaxamento e satisfação foi satisfatória com $80 \%$ de respostas positivas. Todos os participantes afirmaram ter interesse em voltar na atração e indicariam para algum amigo.

- O nível de imersão (envolvimento) no jogo foi alto com cerca de $76 \%$ de respostas positivas. A imersão foi detectada através da variável tempo, onde os participantes não percebiam o tempo passar.

- Os desafios lançados pelos jogos obtiveram $81 \%$ de respostas positivas, mostraram-se adequados às habilidades dos participantes e mantendo neles a vontade de continuar participando.

- O controle, que está relacionado à facilidade de utilização dos dispositivos de interação (botões, joystick e tela touchscreen) obteve $79 \%$ de respostas positivas. Analisando separadamente os três grupos, identificamos que os participantes do grupo que utilizou Botões tiveram um pouco mais de dificuldade para tocar o botão no tempo certo. 
- A interação social, ou seja, envolvimento do participante com os demais colegas durante o jogo, foi satisfatória, $91 \%$ de respostas positivas. Isso mostra que a interação com as pessoas é tão importante quanto a interação com os jogos, havendo assim, mais cooperação e menos individualismo.

Analisando os dois grupos separadamente - FI e FII - não houve grande diferença no que tange a experiência com jogos. Salvo o item interação social, verificou-se que o FI procura cooperar mais com os outros grupos. Observou-se que as crianças mais novas interagem mais, talvez pela naturalidade e desenvoltura que elas possuem comparadas às crianças mais velhas e que favorece para a comunicabilidade com outras crianças. Vale ressaltar que, segundo Ficheman et al. (2008), a cooperação torna-se uma ferramenta eficaz para o trabalho com as crianças, pois pode-se trabalhar a exclusão do sentimento individualista e ressaltar a importância do outro nas relações cotidianas.

Para conhecer o "grau de retenção de informações" ou memorização foi medido o nível de conhecimentos dos estudantes antes (Figura 3a) e depois (Figura 3b) da atividade com os jogos. Pôde-se notar que o número de acertos pós-jogo foi consideravelmente maior que o pré-jogo. Portanto, houve retenção de informação pósjogo. Segundo Antunes (1998), a memória é vinculada de forma dinâmica à atenção: "Todo processo de retenção de informação e aprendizagem está subordinado a dois componentes cerebrais: atenção e memória. A pessoa aprende melhor quando presta mais atenção e, obviamente, joga para a memória a intenção de reter o que aprendeu...”. Como já apresentado, o nível de atenção durante os jogos foi alto e, consequentemente, as informações captadas foram armazenadas na memória.
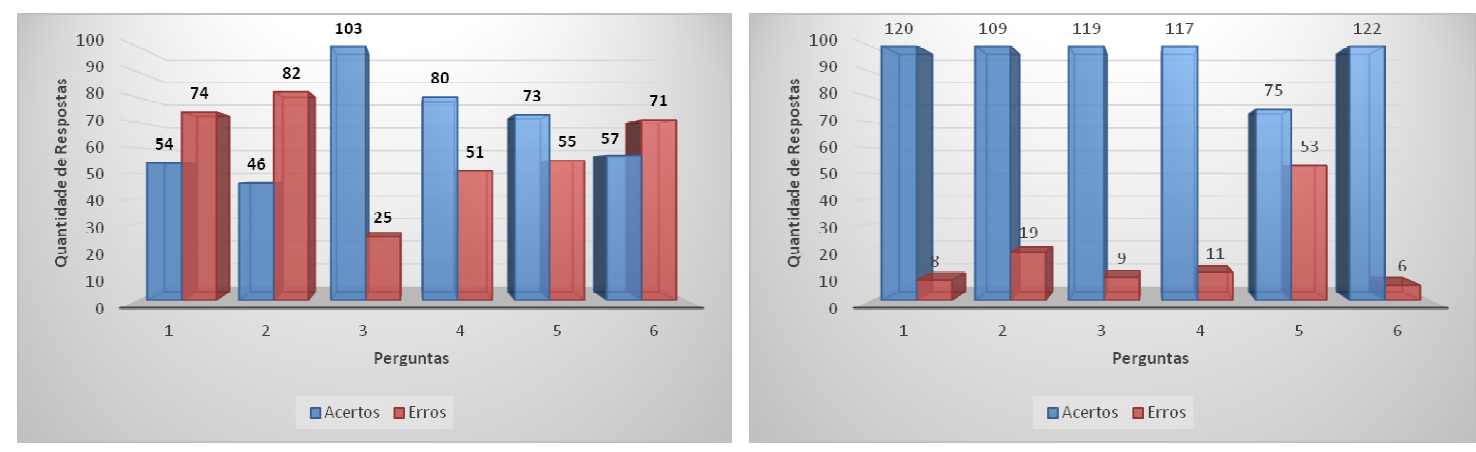

Figura 3. a) Acertos antes do jogo; b) Acertos após o jogo.

Analisando os dois grupos separadamente - FI e FII - pode-se notar que ambas as categorias apresentaram resultados satisfatório semelhantes. Com exceção da pergunta n. 5, "Existe Vida em Marte?", onde a quantidade de respostas certas foi maior no Grupo FI. Supõe-se que essa diferença tenha relação direta com o engajamento e envolvimento no jogo que, como já discutido, foi maior no FI que no FII. Apesar do nível de atenção ter sido satisfatório em ambos os grupos, pode ter ocorrido distração por parte do FII no final do jogo, onde o assunto "Vida em Marte" é tratado: o jogo "salvar o robô em Marte" tem duração de aproximadamente 13 minutos. Nele, os jogadores têm a expectativa de que o robô encontrou vida em Marte. Há vários minijogos e vídeos ao redor desta ideia. Contudo, no final desse jogo o comandante diz que não havia vida em Marte, através de um vídeo explicativo curto, de apenas alguns segundos. Isso pode ter levado os participantes a guardarem a primeira informação (de que pode haver vida em Marte), mas não a segunda (de que não há vida em Marte). Outro ponto a considerar é que, no momento em que o jogo revela que não existe vida 
V Congresso Brasileiro de Informática na Educação (CBIE 2016)

Anais do XXVII Simpósio Brasileiro de Informática na Educação (SBIE 2016)

em Marte, já é o final da atração e as crianças estão vibrando - ou porque ganharam o jogo e estão eufóricos ou porque não ganharam e ficaram lamentando a derrota.

Os dados referentes ao ranking dos melhores jogos foram praticamente iguais no FI e FII, portanto, esses dados foram agrupados (Figura 4). No questionário foi solicitado que cada participante escolhesse até três jogos como preferidos. $89 \%$ dos participantes preferem o jogo "afastar lixo espacial", seguido do jogo "calibrar painéis" e do jogo "levar alimento para a estação espacial". O tipo de dispositivo de interação (touchscreen, joystick e botões).

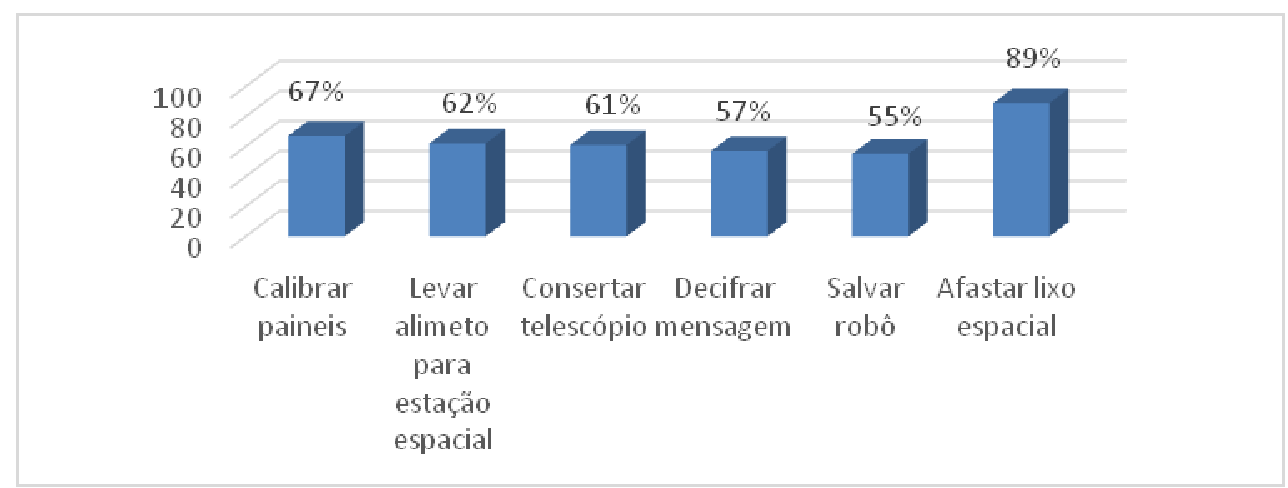

Figura 4. Ranking dos jogos

Com relação ao dispositivo de interação, foi feita uma análise para verificar sua facilidade de interação por tipo de jogo. A tela touchscreen, teve maior aceitação com o jogo "Afastar o Lixo Espacial". Com o joystick os destaques foram os jogos "Calibrar os painéis", "levar alimento para a estação" e "Afastar o Lixo Espacial". Já com os botões, o destaque foi o jogo "Afastar o Lixo Espacial".

\section{Considerações Finais}

Este estudo buscou investigar os ganhos afetivos e cognitivos com os jogos interativos da atração "Aventura no Sistema Solar" do Museu Catavento Cultural e Educacional. Para tanto, foi trabalhada uma amostra 128 estudantes do ensino público, sendo 81 do Fundamental I (FI) e 47 do Fundamental II (FII).

Por meio da construção de um modelo de avaliação, foi possível obter resultados sobre: (a) o nível de motivação dos estudantes ao usarem os jogos; (b) a experiência de utilização dos jogos interativos; e (c) o grau de retenção de informação pós-jogo.

Com relação ao item (a), constatou-se que houve um equilíbrio entre os grupos FI e FII, sendo que ambos mantiveram um alto índice de motivação durante a experiência. Ressalta-se neste item o grande potencial dos jogos para a retenção de conteúdos, visto que o nível de atenção foi alto. Como já mencionado neste trabalho, a atenção (concentração) é um fator essencial para o processo de memorização e, consequentemente, da retenção de informação (item c), que também foi satisfatória. Apesar de trazer influências diretas na aprendizagem, vale ressaltar que a memorização de informações, não implica necessariamente em aquisição de saber. Para que haja aprendizagem, é necessário que o indivíduo saiba aplicar os conhecimentos recémadquiridos em situações reais, que seja capaz de fazer análises e sínteses e que consiga julgar o valor do conhecimento, segundo previsto pela Taxonomia de Bloom (1956). Só assim, o indivíduo será capaz de fazer associações, comparações, classificações, categorizações e generalizações dos novos conhecimentos relacionando-os com os anteriores. 
Com relação ao item $b$, constatou-se que os jogos proporcionam uma boa experiência de utilização. Foi possível notar que o nível dos desafios, propostos pelos jogos, está dentro das habilidades dos estudantes, o que gera nos jogadores a vontade de permanecer jogando ou de jogar outras vezes. Houve boa interação social reforçando a importância dos jogos colaborativos para a consciência da cooperação: parceria, união, confiança, alegria, interdependência, inclusão, companheirismo e bem-estar.

Um ponto a destacar é a necessidade de orientar professores e alunos quanto à finalidade dos museus de ciências para que se desfaça a ideia de visita como "atividade limitada ao lazer", encarada apenas como um passeio, desvinculada da aprendizagem que estes espaços podem propiciar.

Como continuidade deste trabalho, pretende-se reaplicar o modelo de avaliação aqui proposto para avaliar outros espaços interativos, como por exemplo, a atração "Viagem pelo Fundo do Mar", também em exposição no museu Catavento Cultural.

\section{REFERÊNCIAS}

Bloom, B.S. et al. Taxonomy of educational objectives. New York: David Mckay. 262 p., vol. 1, 1956.

Corrêa, A.G.D.; Ficheman, I.K.; Lopes, R.D. "O Fazer Musical de Pessoas com Deficiência: as novas tecnologias propiciando a inclusão". In Anais do $23^{\circ}$ Simpósio Brasileiro de Informática na Educação (SBIE 2012), Rio de Janeiro, 2012.

Ferreira, B.M.; Rivero, L.; Lopes, A.; Marques, A. B.; Conte, T. "UsabiliCity: Um Jogo de Apoio ao Ensino de Propriedades de Usabilidade de Software Através de Analogias". In Anais do III Congresso Brasileiro de Informática na Educação (CBIE 2014) e XXV Simpósio Brasileiro de Informática na Educação (SBIE 2014), pp. Dourados-MS, p. 1273-1282, 2014.

Ficheman, I. K.; Corrêa, A.G.D.; Saul, J.A.; Biazon, L.; Camargo, M.A.; Mantovani, M.S.M.; Zuffo, M.K.; Lopes, R.D. "Uma Aventura no Espaço com a Nave Mário Schenberg: Ambiente Colaborativo em Realidade Virtual para Aprendizagem de Ciências”. In Anais do XIX Simpósio Brasileiro de Informática na Educação (SBIE), 2008, Fortaleza, p. 746-755, 2008.

Henrique, M. S.; Morais, I.S.; Azevedo, S. P.; Albuquerque, V.F.A. "Tabuada da Velha: Um Jogo Educacional Sobre Adição e Subtração". In Anais dos Workshops do IV Congresso Brasileiro de Informática na Educação (CBIE 2015), p. 310-317, 2015.

Keller, J.M. Motivational Design for Learning and Performance: The ARCS Model Approach. Springer, 2009.

Levay, P.; Falcão, T.P.; Diniz, J.; Souza, R. "Uma Experiência de Uso de Jogos Digitais como Ferramentas de Apoio para Aprendizagem de Inglês por Crianças". In Anais do IV Congresso Brasileiro de Informática na Educação, XXI Workshop de Informática na Escola (WIE 2015), p. 207-216, Maceió-AL, 2015.

Lozada A.O., Scarpa D.L., Miranda M.A.G.C. "Trabalho Integrado do Museu Catavento Cultural de São Paulo para o ensino de ciências". Anais de IV Encontro Nacional de Ensino de Biologia (ENEBIO), vol. 1, nº 1, 2012.

Marchi, A.C.B.; Silva, F. B.; Testa, C.D. CV-MUZAR - Uma Comunidade Virtual de Aprendizagem que aproxima os Museus de Ciências Naturais da Escola. In Anais do XXVII Congresso da Sociedade Brasileira de Computação, XIII Workshop sobre Informática na Escola, p. 297-304, Rio de Janeiro, 2007. 
V Congresso Brasileiro de Informática na Educação (CBIE 2016)

Anais do XXVII Simpósio Brasileiro de Informática na Educação (SBIE 2016)

Martinazzo, A.A.G.; Ficheman, I.K.; Venancio, V.; Corrêa, A.G.D.; Lopes, R.D; MANTOVANI, M.S.M. The Mário Schenberg Spaceship: Experiencing Science in a Collaborative Learning VR Environment. In 2009 Ninth IEEE International Conference on Advanced Learning Technologies (ICALT), Riga-Letônia, v. 1. p. 626-628, 2009.

Moreira M. A.; Teorias de Aprendizagem. São Paulo: Editora Pedagógica e Universitária LTDA, 1999.

Pierini, L.M., Valentim. A.C.; Cardoso A. "Brinquedos Numéricos: um jogo para o ensino dos conjuntos numéricos". In Anais do 23 Simpósio Brasileiro de Informática na Educação (SBIE 2012), vol.1, p. 1-8, 2012.

Pontes, H.P. "Desenvolvimento de Jogos no Processo de Aprendizado em Algoritmos e Programação de Computadores". Proceedings of the XII Simpósio Brasileiro de Games e Entretenimento Digital (SBGames), São Paulo, 2013.

Savi, R.; Wangenhem, C.G.; Borgatto, A.F. "Um Modelo de Avaliação de Jogos Educacionais na Engenharia de Software”. In Anais do XXV Simpósio Brasileiro de Engenharia de Software (SBES 2011), São Paulo, 2011.

Savi, R.; Wangenhem, C.G.; Ulbricht, V.; Vanzin T. "Proposta de um Modelo de Avaliação de Jogos Educacionais". In Revista Novas Tecnologias na Educação (RENOTE), vol.8, $\mathrm{n}^{\circ}$ 3, 2010.

Scaico P.; Marques, D.L.; Melo, L.A.; Azevedo, M.A.; Neto, S.V.M., Scaico, A. "Um jogo para o ensino de programação em Python baseado na taxonomia de Bloom." In Anais do Congresso da Sociedade Brasileira de Computação-XX WEI (Workshop de Educação em Informática), 2012.

Valente, M.; Cazellis, S.; Alves, F. "Museus, ciências e educação: novos desafios". Revista História, Ciências, Saúde-Manguinhos, vol.12, p. 183-203, 2005.

Vieira, V.; Bianconi, M.L., Dias, M. "Espaços não-formais de ensino e o currículo de ciências". Revista Sociedade Brasileira para o progresso da Ciência (SBC), vol. 57, $\mathrm{n}^{\circ} 4,2005$. 